\title{
Global systematic review of cost of illness and economic evaluation studies associated with snakebite
}

\author{
Chanthawat Patikorn ${ }^{1}$, Doungporn \\ Leelavanich ${ }^{1}$, Ahmad Khaldun \\ Ismail $^{2}$, Iekhsan Othman ${ }^{3}$, Suthira \\ Taychakhoonavudh ${ }^{1}$, Nathorn \\ Chaiyakunapruk ${ }^{4,5}$
${ }^{1}$ Department of Social and Administrative Pharmacy, Faculty of Pharmaceutical Sciences, Chulalongkorn University, Bangkok, Thailand Tuanku Muhriz Hospital, Universiti Kebang- saan Malaysia Medical Centre, Kuala Lumpur, Malaysia
${ }^{3}$ Neuropharmacology Research Laboratory, Jeffrey Cheah School of Medicine and Health Sciences, Monash University Malaysia, Bandar Sunway, Selangor, Malaysia
${ }^{4}$ College of Pharmacy, University of Utah, Salt Lake City, Utah, USA
${ }^{5}$ School of Pharmacy, Monash University Malaysia, Selangor, Malaysia \\ ${ }^{2}$ Department of Emergency Medicine, Chancellor
}

\section{Correspondence to:}

Nathorn Chaiyakunapruk

Department of Pharmacotherapy, College of

Pharmacy

The University of Utah

302000 E, Salt Lake City

UT, 84112

USA

nathorn.chaiyakunapruk@utah.edu

Suthira Taychakhoonavudh

Department of Social and Administrative

Pharmacy

Faculty of Pharmaceutical Sciences

Chulalongkorn University

254 Phayathai Road Pathumwan

Bangkok, 10330

Thailand

Suthira.T@chula.ac.th

\begin{abstract}
Background Snakebite envenoming, a high priority Neglected Tropical Disease categorized by the World Health Organization (WHO), has been considered as a poverty-related disease that requires greater global awareness and collaboration to establish strategies that effectively decrease economic burdens. This prompts the need for a comprehensive review of the global literature that summarizes the global economic burden and a description of methodology details and their variation. This study aimed to systematically identify studies on cost of illness and economic evaluation associated with snakebites, summarize study findings, and evaluate their methods to provide recommendations for future studies.

Methods We searched PubMed, EMBASE, Cochrane library, and Econlit for articles published from inception to 31 July 2019. Original articles reporting costs or full economic evaluation related with snakebites were included. The methods and reporting quality were assessed. Costs were presented in US dollars (US\$) in 2018.
\end{abstract}

Results Twenty-three cost of illness studies and three economic evaluation studies related to snakebites were included. Majority of studies $(18 / 23,78.26 \%)$ were conducted in Low- and Middle-income countries. Most cost of illness studies (82.61\%) were done using hospital-based data of snakebite patients. While, four studies (17.39\%) estimated costs of snakebites in communities. Five studies $(21.74 \%)$ used societal perspective estimating both direct and indirect costs. Only one study (4.35\%) undertook incidence-based approach to estimate lifetime costs. Only three studies (13.04\%) estimated annual national economic burdens of snakebite which varied drastically from US\$126319 in Burkina Faso to US $\$ 13802550$ in Sri Lanka. Quality of the cost of illness studies were varied and substantially under-reported. All three economic evaluation studies were cost-effectiveness analysis using decision tree model. Two of them assessed cost-effectiveness of having full access to antivenom and reported cost-effective findings.

Conclusions: Economic burdens of snakebite were underestimated and not extensively studied. To accurately capture the economic burdens of snakebites at both the global and local level, hospital data should be collected along with community survey and economic burdens of snakebites should be estimated both in shortterm and long-term period to incorporate the lifetime costs and productivity loss due to premature death, disability, and consequences of snakebites. 
Snakebite envenoming is one of the most overlooked public health issues globally. Even though almost 4.5-5.4 million people are bitten by snakes annually, snake antivenoms are still not readily and sufficiently available especially in the developing region of the world like Sub-Saharan Africa, South-East Asia and South Asia [1]. Snakebite envenoming can result in fatalities; permanent physical disabilities, such as amputation, blindness and kidney failure; and psychological symptoms, such as Post-Traumatic Stress Disorder (PTSD). In 2017, World Health Organization (WHO) has recognized the importance of snakebite envenoming and categorized it as a high priority Neglected Tropical Disease with the goal of facilitating a cooperation and collaboration across countries to establish strategies to effectively decrease the burden of snakebite envenoming [2].

To systematically establish the effective strategies to deal with snakebites as well as prioritize resources for making antivenom available, it is important to know the true burden of the public-health threat posed by snakebites. However, only a few studies have estimated the economic burdens of snakebites and include only some regions of the world [2-5]. This study aimed to summarize the global economic burden of snakebites by systematically identify studies on cost of illness and economic evaluation associated with snakebites as well as evaluate the methods used in these studies. Our findings will generate overall findings and methodological recommendations for future economic studies related to snakebites.

\section{METHODS}

This review followed the Methodological Expectations of Cochrane Intervention Reviews (MECIR) [6] and was reported according to the Preferred Reporting Items for Systematic Reviews and Meta-Analyses (PRISMA) statement [7]. The PRISMA checklist table of this review is provided in Appendix S1 in the Online Supplementary Document. The study protocol was submitted to PROSPERO for registration (CRD42020147299).

\section{Data source, search strategy, and eligibility criteria}

We searched the following four electronic bibliographic databases; PubMed, Embase, Cochrane Library, and EconLit to identify articles related to cost of illness and economic evaluations associated with snakebites from any country which were published from inception to 31 July 2019. The search term used was snake* AND (burden OR economic* OR cost* OR "cost of illness" OR resource OR expenditure OR "economic evaluation" OR "cost-effectiveness" OR "cost-utility" OR "cost-benefit"). There was no language restriction in this review. Additional searches were done on the health economic databases including Health Economic Evaluation Database (HEED), Cost-effectiveness Analysis Registry, and Health Technology Assessment Database. The detail search strategies are provided in Appendix S2 in the Online Supplementary Document. To be included, study must meet the following inclusion criteria; original articles reporting costs associated with snakebites estimated by primary data collection and original articles of the full economic evaluations associated with snakebites.

\section{Study selection and data extraction}

Two reviewers (CP and DL) independently performed the screening of titles and abstracts for relevance. The full-text articles of the potentially eligible studies were retrieved and selected based on the eligibility criteria by two independent reviewers (CP and DL). Data extraction were performed by two independent reviewers (CP and DL) using the data extraction form in MS Excel (Microsoft Inc, Seattle WA, USA). Discrepancies were discussed among reviewers and resolved by the third reviewer (ST). Methodological characteristics and study findings from the cost of illness studies and economic evaluations were extracted. We extracted the following data from cost of illness studies; study design, country, setting, study period/ duration, sample size, perspective, data source, cost estimation method, cost components, currency year, snake species, antivenoms, and cost estimates. The following data were extracted from economic evaluation studies; target population, study perspective, comparators, time horizon, discount rate, choice of health outcomes, resource and cost estimation method, currency year, choice of model, sensitivity analyses, snake species, antivenoms, study parameters, incremental costs and outcomes.

\section{Quality assessment}

Two independent reviewers (CP and DL) assessed the quality of the studies. Cost of illness studies were assessed using the cost-of-illness evaluation checklist by Larg and Moss [8]. Economic evaluations were 
assessed using the ten-item Drummond checklist [9] and the 24-item Consolidated Health Economic Evaluation Reporting Standards (CHEERS) checklist [10].

\section{Data synthesis}

Methodological characteristics, study findings, and quality of the studies were summarized and presented. Countries were classified by income level according to the World Bank [11]. Costs were presented according to the recommendations of Turner et al., 2019 [12]. For studies that did not provide the year of cost data, the year of publication was used. Adjustment for inflation was done using the Gross Domestic Product (GDP) deflator of the studied country. Cost estimates were then converted and reported in 2018 US dollars (US\$). To further facilitate comparison of costs across countries, the total costs associated with snakebites were estimated as percentage of the country's GDP in 2018. GDP deflator, exchange rate, and GDP were obtained from the World Bank [13-15].

\section{RESULTS}

\section{Study selection}

We identified 3237 articles through electronic database searches. The searches in health economic databases found no additional articles. The detailed process of electronic database searching is presented in Appendix S2 in the Online Supplementary Document. We included 26 studies which met the eligibility criteria as shown in Figure 1. The included studies comprised of 23 cost of illness studies and 3 economic evaluations. Cost of illness studies were done in 16 countries, of which mainly comprised 13 low- and middle-income countries. Only five studies (21.74\%) were conducted in high-income countries. [16-20] Economic evaluation studies were done in India, Nigeria, and 16 West African countries [21-23].

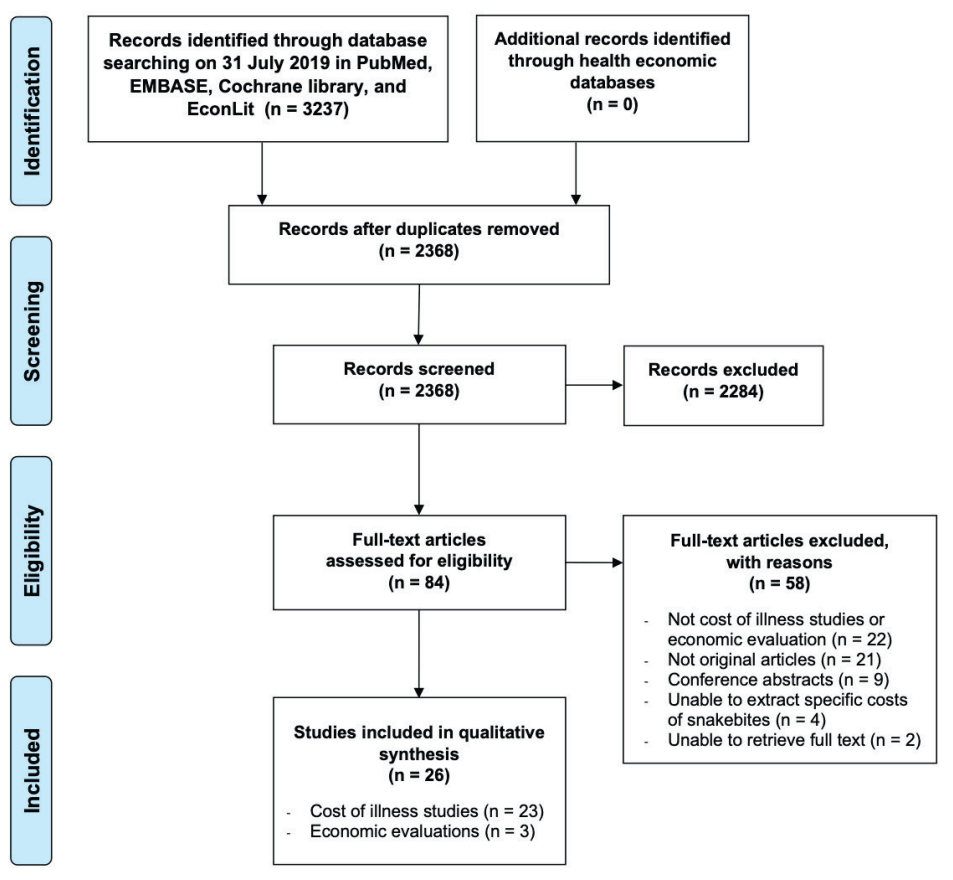

Figure 1. Study selection flow.

\section{Study characteristics}

The description of the study characteristics of the included studies are presented in detail in Appendix S3-S4 in the Online Supplementary Document. Of the 23 cost of illness studies, only 3 studies (13.04\%) estimated annual national economic burdens of snakebite (Table 1) $[5,28,40]$. Nineteen studies (82.61\%) were hospital-based study as they included only snakebite patients presented at hospitals [16-20,25-29,31-34,36-40]. While the remaining four studies (17.39\%) considered snakebite victims in the communities to also include those who did not reach treatment facilities eg, deaths or those who seek traditional healers $[5,24,30,35]$. Among these studies, only one study (4.35\%) holistically collected both hospital-based and community-based data [5].

Most studies (95.65\%) undertook prevalence-based approach which costs of illness of all prevalent cases in the specific period of the study, usually one episode of snakebite, were estimated [5,16-20,24$27,29-40]$. Only one study (4.35\%) undertook inci-

dence-based approach to estimate lifetime costs of illness including costs of productivity loss due to snakebite, disability, and premature death [28].

In terms of study perspectives, five studies (21.74\%) utilized societal perspective which included both direct and indirect costs $[5,19,25,28,37]$. Components of indirect costs reported in the included studies were costs of productivity loss due to premature death and disability, income loss, and family income loss. Conversely, direct medical costs especially antivenom costs were estimated in all studies. Direct medical cost components estimated varied across studies. For example, traditional healer costs were reported in three studies (13.04\%), [5,24,35] while six studies (26.09\%) estimated direct non-medical costs including costs of transportation, communication, food, accommodation, and caregivers [5,25,27,29,33,35]. 


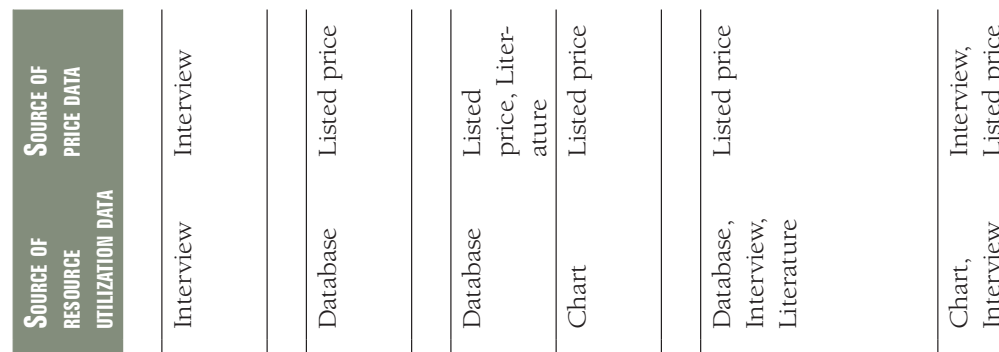
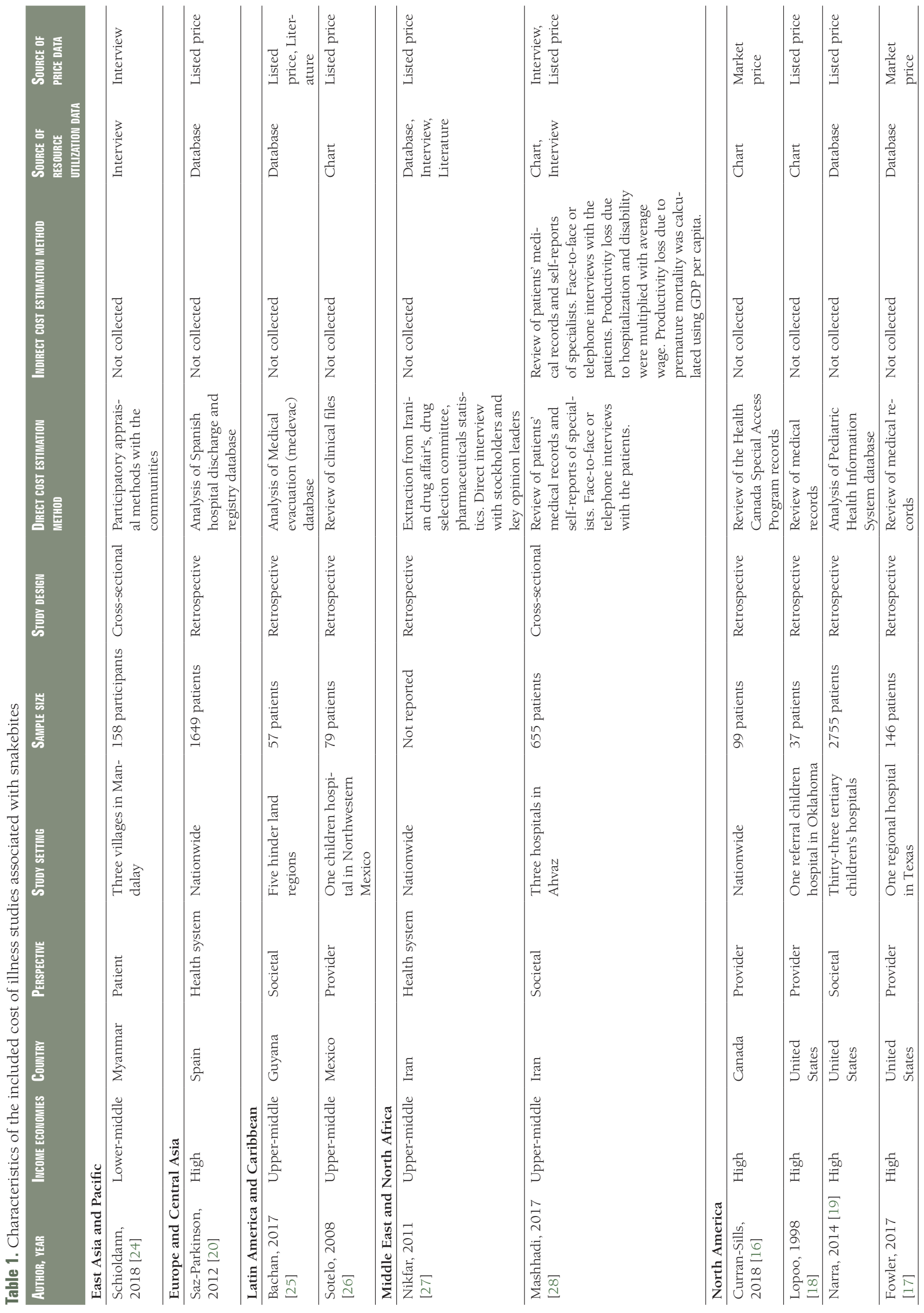


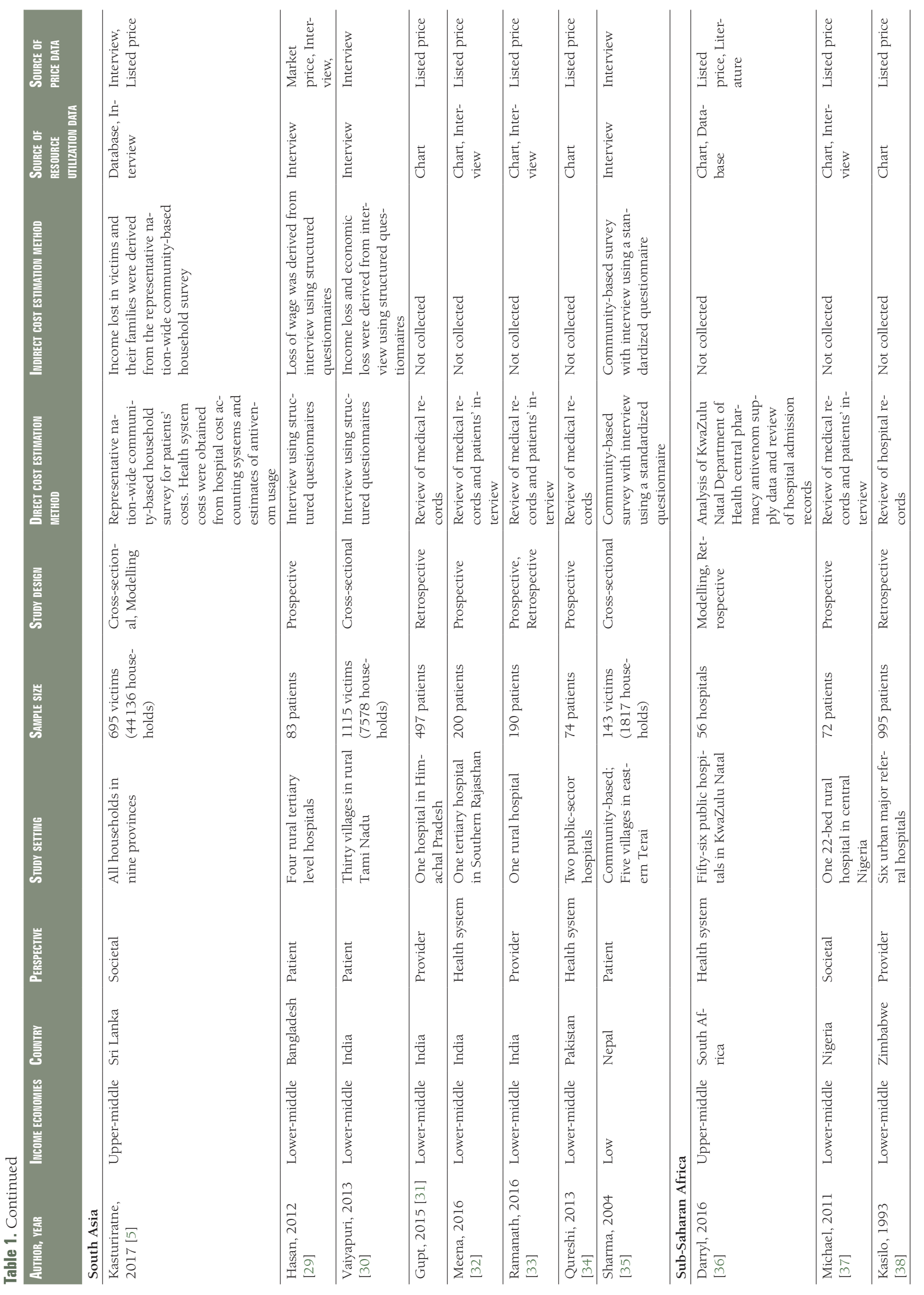




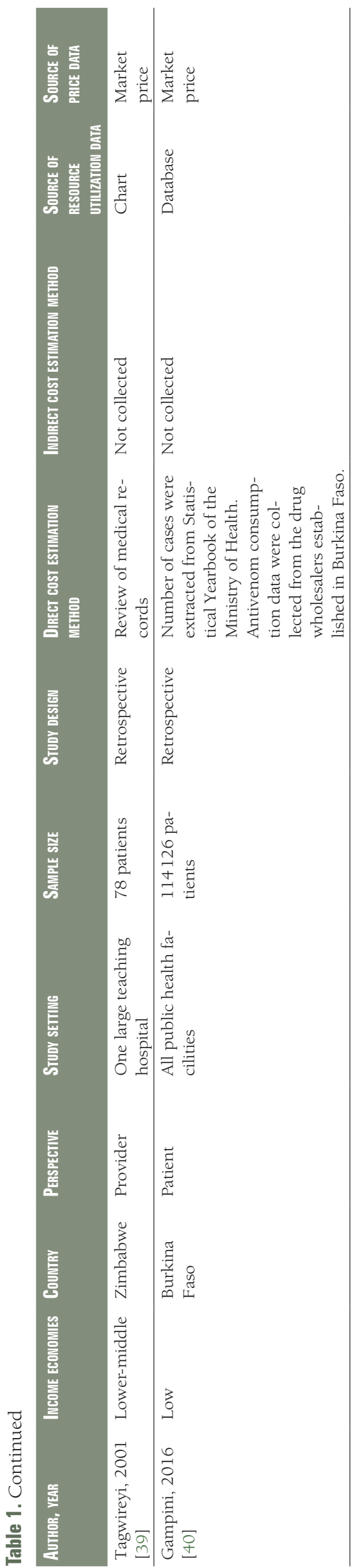

All of the reported cost components are summarized in Appendix S5 in the Online Supplementary Document.

Multiple sources of information were used to quantify, and value health care resources utilized by snakebite patients. Sources of health care resource utilization data were chart, database, interview, and literature. Chart $(\mathrm{n}=12$, $52.17 \%)[16,18,26,28,31-34,36-39]$ and interview $(n=10,43.48 \%)[5,24,27-$ $30,32,33,35,37]$ were the most commonly used sources. Prices of health care resources were from interview, listed price, literature, and market price. Listed price was the most common source of price data $(n=15,65.22 \%)[5,18$ 20,25-28,31-34,36-38].

Only three economic evaluation studies were identified. All of them were cost-effectiveness analysis using decision analytic models [21-23]. Two studies compared no access to antivenom to full access in envenomed snakebite patients presented to hospital $[21,22]$. While, another study compared antivenom alone with the antivenom adjunct combination strategy to improve the proportion of snake victims reaching health care facilities [23]. The health outcomes of snakebite in the models were similar including full recovery, death, and amputation. Lifelong was selected as the time horizon to capture deaths and disabilities. Discount was applied only to outcomes because direct costs of snakebite normally occurred during treatment in health care facilities [21-23].

\section{Quality assessment}

Reporting quality of the included studies was assessed and presented in Appendix S6-S7 in the Online Supplementary Document. Reporting quality of the included cost of illness studies were substantially varied. Perspective, epidemiologic approach, health care resource valuation, and detail cost components were not clearly specified and reported. None of the included studies performed sensitivity analysis or estimated intangible costs. In contrast, reporting quality of the included economic evaluation studies was high where most aspects were met by all three studies [21-23].

\section{Annual national cost estimates of snakebite}

Among the included cost of illness studies, three studies estimated costs of snakebites as annual national costs in Iran, Sri Lanka, and Burkina Faso $[5,28,40]$. Table 2 shows the annual national cost estimates of snakebite in US $\$ 2018$, cost breakdowns, and their contribution to the total costs. The number of snakebite patients ranged from 5379 patient in Iran [28] to 80277 patients in Sri Lanka [5]. These numbers were either retrieved from annual report or extrapolated and estimated from studies. The total annual national costs of snakebite drastically varied from US\$126319 in Burkina Faso [40] to US $\$ 13802550$ in Sri Lanka [5]. These three studies estimated the annual national economic burdens of snakebite, of which direct medical costs contributed the most to the total costs (68.01\%-77.14\%) followed by indirect costs (13.16\%-24.86\%), and direct non-medical costs (7.13\%-9.70\%) $[5,28,40]$. Moreover, the total annual national costs from three countries were then calculated as percentage of the countrys GDP in 2018 which resulted in less than $0.001 \%$ in Iran and Burkina Faso and $0.016 \%$ in Sri Lanka. Average cost estimates per patient per episode of snakebite were summarized in US\$2018 in Appendix S8 in the Online Supplementary Document.

\section{Findings of economic evaluation studies associated with snakebite}

Two studies reported outcomes as Disability-adjusted life years (DALYs) and deaths from snakebite [21,22], while the other study reported only DALYs [23]. All three studies concluded that their interventions were very-cost-ef- 
Table 2. Annual national cost estimates of snakebite in US\$, 2018

\begin{tabular}{|c|c|c|c|c|c|c|c|c|c|}
\hline \multirow{2}{*}{ AUtHOR, YeAr } & \multirow{2}{*}{ Country } & \multirow{2}{*}{ Perspective } & \multirow{2}{*}{ Study approach } & \multirow{2}{*}{$\begin{array}{l}\text { AnNUAL } \\
\text { nUMBER OF } \\
\text { SHAKEBITE } \\
\text { PATIENTS }\end{array}$} & \multirow{2}{*}{$\begin{array}{l}\text { SoURGE OF ANNUAL } \\
\text { INCIDENT CASES }\end{array}$} & \multicolumn{4}{|c|}{$\begin{array}{l}\text { AnNuAL national cost ESTIMATES IN US\$2018 WITH COSt CONTRIBUTION TO TOTAL } \\
\text { COSTS }\end{array}$} \\
\hline & & & & & & $\begin{array}{l}\text { Direct medical } \\
\text { costs }(\%)\end{array}$ & $\begin{array}{l}\text { Direct non-med- } \\
\text { ical costs }(\%)\end{array}$ & $\begin{array}{l}\text { Indirect } \\
\text { costs }(\%)\end{array}$ & Total costs \\
\hline $\begin{array}{l}\text { Mashhadi, } \\
2017[28]\end{array}$ & Iran & Societal & Incidence-based & 5,379 & Annual report & $\begin{array}{l}2658464 \\
(68.01 \%)\end{array}$ & $\begin{array}{l}278665 \\
(7.13 \%)\end{array}$ & $\begin{array}{l}971612 \\
(24.86 \%)\end{array}$ & $3,908,741$ \\
\hline $\begin{array}{l}\text { Kastur- } \\
\text { iratne, } \\
2017 \text { [5] }\end{array}$ & $\begin{array}{l}\text { Sri } \\
\text { Lanka }\end{array}$ & Societal & Prevalence-based & 80,277 & $\begin{array}{l}\text { Extrapolated } \\
\text { from commu- } \\
\text { nity survey and } \\
\text { previous studies }\end{array}$ & $\begin{array}{c}10647355 \\
(77.14 \%)\end{array}$ & $\begin{array}{c}1338614 \\
(9.70 \%)\end{array}$ & $\begin{array}{l}181,6581 \\
(13.16 \%)\end{array}$ & $13,802,550$ \\
\hline $\begin{array}{l}\text { Gampini, } \\
2016[40]\end{array}$ & $\begin{array}{l}\text { Burkina } \\
\text { Faso }\end{array}$ & Patients & Prevalence-based & 22,337 & $\begin{array}{l}\text { Estimated from } \\
\text { previous studies }\end{array}$ & $\begin{array}{c}126319 \\
(100.00 \%)\end{array}$ & NR & NR & 126,319 \\
\hline
\end{tabular}

N/A - not applicable, NR - not reported

fective because the Incremental Cost-Effectiveness Ratio (ICER) per DALY averted of these studies ranged from 69.87 to 256.62 US\$, which were much below the willingness-to-pay threshold of one GDP per capita of US\$351.60 to US\$2504.14 in the study countries [21-23]. While, the ICER per death averted of two studies ranged from US\$1634.40 to US\$5666.75 [21,22]. Costs of antivenom $[21,22]$ and proportion of patients with severe envenomation [23] were the most sensitive parameters (Appendix S9 in the Online Supplementary Document).

\section{DISCUSSION}

Accurate and comprehensive estimations of economic burdens of snakebites are highly needed to demonstrate the real impact of this neglected tropical disease. Revealing the economic burdens of snakebites will make the policymakers understand the magnitude and contribution of each cost component. Moreover, the cost estimates derived can be further utilized in the subsequent economic evaluation studies which accurate cost estimates will result in less uncertain economic models. Thus, strategies and resources could be better developed and allocated to effectively deal with snakebites.

This review is the first systematic review which comprehensively identified economic studies related to snakebites in published literature. The methodological characteristics and study findings were summarized. Our review found that 23 cost of illness studies and 3 economic evaluations had been conducted so far. Majority of these studies were conducted in Low- and Middle-income countries in regions highly inhabited by snakes. However, the overall methods of the included cost of illness studies related to snakebites were not comprehensive as most of them estimated only non-national direct costs in the hospital setting from non-societal perspectives.

Based on our review findings, several methodological issues should be considered for future research on economic burden estimation. First, the economic burden studies of snakebites should be done from the societal perspective in the national level to fully capture both direct and indirect costs and their relevant cost components. Our review found that collecting only direct medical costs could only capture $68.01 \%$ $77.14 \%$ of the national annual total costs of snakebites. Direct non-medical costs and indirect costs contribute $7.13 \%-9.07 \%$ and $13.16 \%-24.86 \%$, respectively $[5,28,40]$.

Second, economic burden studies should capture all snakebite victims by using both hospital-based and community-based data to ensure that those not seeking medical care are included. Hospital-based studies mostly captured envenomed or severe snakebite victims who were more likely to go to hospital. Therefore, incorporating the community-based survey could further improve the completeness of the economic burdens because not all of the victims could reach hospital. They may die beforehand due to long travel distances, be referred to higher level health care facilities, or seek traditional healers for help due to cultural belief $[5,24,30,35]$. For example, it was found that approximately $45.2 \%$ of snakebite victims in Sri Lanka consulted traditional healers which could further delay access to effective antivenom and result in worse outcomes [41]. Therefore, victim transportation and treatment seeking behavior should also be incorporated into the analysis depending on each country. If national epidemiological data of snakebites is lacking, data collection could be done in a representative group of snakebite victims then appropriately extrapolate to national cost estimates. 
Third, although snakebites are episodic and most costs occur during the first few weeks, economic burdens of snakebites should be estimated both in short-term and long-term period to take into account the lifetime costs and productivity loss due to premature death and disability. Estimating indirect costs only in the short-term period as income loss might underestimate the indirect costs of snakebites. The contribution of indirect cost estimates to the total costs increased from $13.16 \%$ to $24.86 \%$ when long-term costs of productivity loss due to premature death and disability from snakebite were incorporated $[5,28,40]$.

Lastly, consequences of snakebites should be broader to include all relevant disabilities and their following costs and productivity loss such as premature death, amputation, blindness, kidney failure, malignant ulcers, pregnancy loss, scarring, and PTSD [21]. These will be varied by species of venomous snakes within each country. Therefore, all important snake species and their geographical distribution should also be considered to capture all relevant costs and consequences of snakebites.

Our systematic review has several limitations that should be discussed. The quality assessment of the included cost of illness studies could only be done in the aspects of reporting quality, since there are no guidelines or checklist to directly evaluate the methodological quality of the cost of illness studies. Nonetheless, articles with good reporting quality could imply their methodological quality to some extent. Moreover, the global economic burdens of snakebites and country comparison could not be estimated due to the underestimated nature of snakebite economic burdens revealed from our review. Further research should be conducted using both hospital-based and community-based data to gather and highlight the overlooked global economic burdens of this neglected tropical disease taking into account our methodological recommendations.

\section{CONCLUSION}

Economic burdens of snakebite were underestimated and not extensively studied. Majority of studies only provided direct costs of snakebite patients presented to the hospitals. There was a lack of study estimating national economic burdens of snakebites. Due to likely underestimated economic burden, hospital data should be used to combine with community survey to ensure the accurate estimation of overall economic burdens of snakebite victims. Having full access to antivenom was found to be very cost-effective. Future studies should focus on how to make antivenoms available and affordable to snakebite victims.

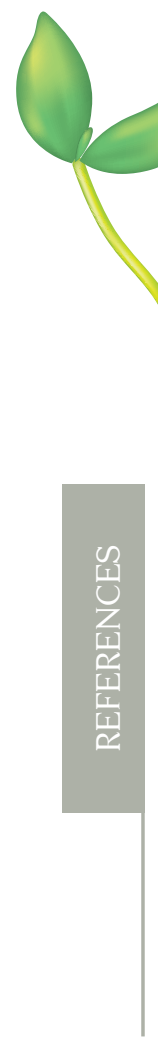

Funding: This systematic review was done without any financial support.

Authorship contributions: Conceived and designed the study protocol: CP, ST, IO, NC. Performed systematic review: CP, ST, DL, NC. Wrote the paper: CP, ST, DL, AI, IO, NC.

Competing interests: The authors completed the ICMJE Unified Competing Interest form (available upon request from the corresponding author), and declare no conflicts of interest.

Additional material

Online Supplementary Document

1 World Health Organization. Snakebite envenoming: Prevalence of snakebite envenoming. 2019. Available: https://www. who.int/snakebites/epidemiology/en/. Accessed: 23 October 2019.

2 World Health Organization. Global snakebite burden. 2018. Available: http://apps.who.int/gb/ebwha/pdf_files/WHA71/ A71_17-en.pdf. Accessed: 23 October 2019.

3 Gampini S, Nassouri S, Chippaux J-P, Semde R. Retrospective study on the incidence of envenomation and accessibility to antivenom in Burkina Faso. J Venom Anim Toxins Incl Trop Dis. 2016;22:10. Medline:26985188 doi:10.1186/ s40409-016-0066-7

4 Mohapatra B, Warrell DA, Suraweera W, Bhatia P, Dhingra N, Jotkar RM, et al. Snakebite mortality in India: a nationally representative mortality survey. PLoS Negl Trop Dis. 2011;5:e1018. Medline:21532748 doi:10.1371/journal.pntd.0001018

5 Kasturiratne A, Pathmeswaran A, Wickremasinghe AR, Jayamanne SF, Dawson A, Isbister GK, et al. The socio-economic burden of snakebite in Sri Lanka. PLoS Negl Trop Dis. 2017;11:e0005647. Medline:28683119 doi:10.1371/journal. pntd.0005647

6 Higgins J, Lasserson T, Chandler J, Tovey D, Thomas J, Flemyng E, et al. Standards for the conduct of new Cochrane Intervention Reviews. In: Higgins JPT, Lasserson T, Chandler J, Tovey D, Thomas J, Flemyng E, Churchill R.Methodological Expectations of Cochrane Intervention Reviews. Cochrane: London, March 2020. 
7 Moher D, Liberati A, Tetzlaff J, Altman DG. Preferred reporting items for systematic reviews and meta-analyses: the PRISMA statement. Ann Intern Med. 2009;151:264-9. Medline:19622511 doi:10.7326/0003-4819-151-4-20090818000135

8 Larg A, Moss JR. Cost-of-illness studies: a guide to critical evaluation. Pharmacoeconomics. 2011;29:653-71. Medline:21604822 doi:10.2165/11588380-000000000-00000

9 Drummond MF, Sculpher MJ, Claxton K, Stoddart GL, Torrance GW. Methods for the economic evaluation of health care programmes. Oxford: Oxford University Press; 2015.

10 Husereau D, Drummond M, Petrou S, Carswell C, Moher D, Greenberg D, et al. Consolidated Health Economic Evaluation Reporting Standards (CHEERS) statement. Value Health. 2013;16:e1-5. Medline:23538200 doi:10.1016/j. jval.2013.02.010

11 The World Bank. World Bank Country and Lending Groups - Country Classification. 2019. Available: https://datahelpdesk. worldbank.org/knowledgebase/articles/906519-world-bank-country-and-lending-groups. Accessed: 23 October 2019.

12 Turner HC, Lauer JA, Tran BX, Teerawattananon Y, Jit M. Adjusting for Inflation and Currency Changes Within Health Economic Studies. Value Health. 201922:1026-32. Medline:31511179 doi:10.1016/j.jval.2019.03.021

13 The World Bank. Inflation, GDP deflator: linked series (annual \%). 2019. Available: https://data.worldbank.org/indicator/ NY.GDP.DEFL.KD.ZG.AD. Accessed: 20 October 2019.

14 The World Bank. Official exchange rate (LCU per US\$, period average). 2019. Available: https://data.worldbank.org/ indicator/PA.NUS.FCRF. Accessed: 20 October 2019

15 The World Bank. GDP (current US\$). 2019. Available: https://data.worldbank.org/indicator/ny.gdp.mktp.cd. Accessed: 20 October 2019.

16 Curran-Sills G, Kroeker J. Venomous Snakebites in Canada: A National Review of Patient Epidemiology and Antivenom Usage. Wilderness Environ Med. 2018;29:437-45. Medline:30292560 doi:10.1016/j.wem.2018.06.005

17 Fowler AL, Hughes DW, Muir MT, VanWert EM, Gamboa CD, Myers JG. Resource Utilization After Snakebite Severity Score Implementation into Treatment Algorithm of Crotaline Bite. J Emerg Med. 2017;53:854-61. Medline:29102095 doi:10.1016/j.jemermed.2017.08.095

18 Lopoo JB, Bealer JF, Mantor PC, Tuggle DW. Treating the snakebitten child in North America: a study of pit viper bites. J Pediatr Surg. 1998;33:1593-5. Medline:9856873 doi:10.1016/S0022-3468(98)90587-5

19 Narra A, Lie E, Hall M, Macy M, Alpern E, Shah SS, et al. Resource utilization of pediatric patients exposed to venom. Hosp Pediatr. 2014;4:276-82. Medline:25318109 doi:10.1542/hpeds.2014-0010

20 Saz-Parkinson Z, del Pino Luengo M, Lopez-Cuadrado T, Andujar D, Carmona-Alferez R, Flores RM, et al. Approach to the epidemiology of venomous bites in Spain. Toxicon. 2012;60:706-11. Medline:22484223 doi:10.1016/j. toxicon.2012.03.021

21 Habib AG, Lamorde M, Dalhat MM, Habib ZG, Kuznik A. Cost-effectiveness of antivenoms for snakebite envenoming in Nigeria. PLoS Negl Trop Dis. 2015;9:e3381. Medline:25569252 doi:10.1371/journal.pntd.0003381

22 Hamza M, Idris MA, Maiyaki MB, Lamorde M, Chippaux JP, Warrell DA, et al. Cost-Effectiveness of Antivenoms for Snakebite Envenoming in 16 Countries in West Africa. PLoS Negl Trop Dis. 2016;10:e0004568. Medline:27027633 doi:10.1371/journal.pntd.0004568

23 Herzel BJ, Samuel SP, Bulfone TC, Raj CS, Lewin M, Kahn JG. Snakebite: An Exploratory Cost-Effectiveness Analysis of Adjunct Treatment Strategies. Am J Trop Med Hyg. 2018;99:404-12. Medline:29869597 doi:10.4269/ajtmh.17-0922

24 Schioldann E, Mahmood MA, Kyaw MM, Halliday D, Thwin KT, Chit NN, et al. Why snakebite patients in Myanmar seek traditional healers despite availability of biomedical care at hospitals? Community perspectives on reasons. PLoS Negl Trop Dis. 2018;12:e0006299. Medline:29489824 doi:10.1371/journal.pntd.0006299

25 Bachan V, Tatkan G, Adu-Krow W. Transportation (medical evacuations) of snake bitten persons from the Hinterland Regions in Guyana: Cost analysis. West Indian Med J. 2017;66:43.

26 Sotelo N. Review of treatment and complications in 79 children with rattlesnake bite. Clin Pediatr (Phila). 2008;47:4839. Medline:18192639 doi:10.1177/0009922807311734

27 Nikfar S, Khatibi M, Abdollahi-Asl A, Abdollahi M. Cost and utilization study of antidotes: An Iranian experience. Int J Pharmacol. 2011;7:46-9. doi:10.3923/ijp.2011.46.49

28 Mashhadi I, Kavousi Z, Peymani P, Salman Zadeh Ramhormozi S, Keshavarz K. Economic burden of scorpion sting and snake bite from a social perspective in Iran. Shiraz E Med J. 2017;18:e57573. doi:10.5812/semj.57573

29 Hasan SM, Basher A, Molla AA, Sultana NK, Faiz MA. The impact of snake bite on household economy in Bangladesh. Trop Doct. 2012;42:41-3. Medline:22223726 doi:10.1258/td.2011.110137

30 Vaiyapuri S, Vaiyapuri R, Ashokan R, Ramasamy K, Nattamaisundar K, Jeyaraj A, et al. Snakebite and its socio-economic impact on the rural population of Tamil Nadu, India. PLoS One. 2013;8:e80090. Medline:24278244 doi:10.1371/ journal.pone.0080090

31 Gupt A, Bhatnagar T, Murthy BN. Epidemiological profile and management of snakebite cases - A cross sectional study from Himachal Pradesh, India. Clin Epidemiol Glob Health. 2015;3:S96-100. doi:10.1016/j.cegh.2015.11.007

32 Meena VK, Atray M, Agrawal A. Evaluation of drug utilization pattern in indoor patients of medicine department at tertiary care teaching hospital in southern Rajasthan. Int J Pharma Sci. 2016;7:3835-40.

33 Ramanath KV, Anitha C, Junied S. Study on snake bite poisoning and it's outcomes in a Rural Tertiary Care Hospital. Res J Pharm Biol Chem Sci. 2016;7:1875-89

34 Qureshi H, Alam SE, Mustufa MA, Nomani NK, Asnani JL, Sharif M. Comparative cost and efficacy trial of Pakistani versus Indian anti snake venom. J Pak Med Assoc. 2013;63:1129-32. Medline:24601191 
35 Sharma SK, Chappuis F, Jha N, Bovier PA, Loutan L, Koirala S. Impact of snake bites and determinants of fatal outcomes in Southeastern Nepal. Am J Trop Med Hyg. 2004;71:234-8. Medline:15306717 doi:10.4269/ajtmh.2004.71.234

36 Darryl W, Sartorius B, Hift R. Estimating the Burden of Snakebite on Public Hospitals in KwaZulu Natal, South Africa. Wilderness Environ Med. 2016;27:53-61. Medline:26948554 doi:10.1016/j.wem.2015.11.005

37 Michael GC, Thacher TD, Shehu MI. The effect of pre-hospital care for venomous snake bite on outcome in Nigeria. Trans R Soc Trop Med Hyg. 2011;105:95-101. Medline:21035155 doi:10.1016/j.trstmh.2010.09.005

38 Kasilo OM, Nhachi CF. A retrospective study of poisoning due to snake venom in Zimbabwe. Hum Exp Toxicol. 1993;12:15-8. Medline:8094964 doi:10.1177/096032719301200103

39 Tagwireyi DD, Ball DE, Nhachi CF. Routine prophylactic antibiotic use in the management of snakebite. BMC Clin Pharmacol. 2001;1:4. Medline:11710972 doi:10.1186/1472-6904-1-4

40 Gampini S, Nassouri S, Chippaux JP, Semde R. Retrospective study on the incidence of envenomation and accessibility to antivenom in Burkina Faso. J Venom Anim Toxins Incl Trop Dis. 2016;22:10. Medline:26985188 doi:10.1186/ s40409-016-0066-7

41 Ediriweera DS, Kasturiratne A, Pathmeswaran A, Gunawardena NK, Jayamanne SF, Lalloo DG, et al. Health seeking behavior following snakebites in Sri Lanka: Results of an island wide community based survey. PLoS Negl Trop Dis. 2017;11:e0006073. Medline:29108023 doi:10.1371/journal.pntd.0006073 